\title{
Innovative Seismic Isolation System of Equal Section Multi-span Continuous Beam Bridge with LRB and FVD: Numerical Simulation and Engineering Implementation
}

\author{
TANG Feng ${ }^{1}$,LI Dejian², LU Yao², MA Heng',a, LV Fei², LI Cheng ${ }^{1}$ \\ ${ }^{1}$ Second Engineering Co.Ltd of CCCC Fourth Highway Engineering Co.Ltd, Beijing 101149, \\ China; \\ ${ }^{2}$ School of Civil Engineering, Central South University, Changsha, Hunan 410075, China
}

${ }^{a}$ E-mail address: maheng0731@163.com

\begin{abstract}
Keywords: Equal section multi-span continuous beam bridge; Seismic isolation; Lead-rubber bearings (LRB); Fluid viscous damper (FVD); Nonlinear dynamic time-history analysis

Abstract. Lead-rubber bearing (LRB) has small horizontal resistance under creep loads, and its post-yield stiffness reduces quickly under seismic excitations, while the hysteretic behavior of lead core dissipates the seismic energy; Fluid viscous damper (FVD), which is a speed-related energy dissipation device, could provide strong resilience and excellent position-limiting capability. Both devices above are widely used in seismic mitigation and isolation at present. In this paper, three analytical models based on a highway multi-span continuous beam bridge under E2 earthquake were established, two of which adopt LRB and FVD respectively and the other one use both devices. Longitudinal and transverse seismic response were obtained by use of time-history dynamic analysis. The result indicates that LRB can improve performance of bridge transverse dynamic response under earthquake motion but fail to reduce longitudinal seismic response and FVD has capability of diminishing longitudinal seismic response. According to the comparison of behavior of three analytical models under E2 earthquake, the combined use of LRB and FVD is an effective way of seismic design of equal section multi-span continuous bridge.
\end{abstract}

\section{Introduction}

Earthquake attacks us frequently in recent years and the study of seismic resistance become increasingly important because of the immeasurable damage caused by earthquake directly and indirectly. Bridge, regarded as a lifeline to the outside word of earthquake victims, has to ensure its safety and traffic function after earthquake shock. The seismic isolation design of bridge structure become a hot part of seismic design because of its lower expense than strength design and easier to repair after strong earthquake than ductility design [1]. A reasonable seismic isolation design of bridge can reduce seismic response of structure apparently. Nowadays, Multi-span continuous beam bridge is becoming a new favorite of bridge designer, which is widely used in highway bridge and approach span of long span bridge because of its large rigidity, small deformation, reasonable strength characteristic, simple structure, convenience of construct and low costs. Seismic isolation design of this kind of bridge is significant and can protect it from pier destruction and beam falling under earthquake. The prominent device of seismic isolation and mitigation such as LRB and FVD were widely and successfully used in construction and extensively reported in literatures. And the United State, Japan, Europe and China have incorporated isolation technology into codes [2-5].

Researchers all over the world have done a lot of works about calculation, simulation and application of seismic isolation system. M.C. Constantinou and Allaoua Kartoum analyzed the behavior of hollow circular elastomeric bearing under compression [6]. James M. Kelly, Ian D. Aiken used earthquake simulator to test large-scale model of isolated bridge adopting different isolation systems including high-damping natural-rubber bearings, lead—rubber bearings, sliding bearings, and bearings incorporating uplift resistance mechanisms [7]. A. Mori A.J. Carr, N. Cooke, P.J. Moss investigated the laminated elastomeric bearings and lead-rubber bearings in order to obtain a better understanding of the real bearing behavior under compression load when used in a seismic-isolation system [8]. J.S. Hwang, K.C. Chang, M.H. Tsai investigated equivalent damping 
of regular bridge and estimated the influence on seismic response with different design parameters of isolating device such as mass, stiffness and viscous damping [9].

New Zealand and Italy are the pioneers of study and application of isolation technology and the first built isolated bridge is Moto bridge which located in New Zealand. In recent years, New Zealand have used isolation system especially the device with lead core to dissipate energy in 42 bridges and 3 buildings [10,11]. Unlike Italy, having a tendency to adopt elastic and plastic energy dissipation device, other countries always use LRB between substructure and beam to reduce the dynamic response or redistribute horizontal force. The isolation technology has a mushroom growth in China with the booming construction of railway and highway in twenty-first century. The BuGuZi railway bridge isolated by LRB, in southern part of XinJiang province, is the first built isolated bridge in China which stood up through the BaChu-KaShi earthquake in 2003 and played an important role in the rescue. Alongside with the application of LRB, FVD has also been widely used in more than 20 bridges such as SuTong bridge and XiHouMen bridge and highly appreciated in bridge engineering $[12,13]$. However, the focus of research of isolation technology is mostly on simulating the mechanical property of isolators $[14,15]$ and the unidirectional seismic design is predominant in recent years. The combined use of several devices and isolation design both in longitudinal and transverse direction need some further research.

FVD has little contribution to transverse mitigation of straight line bridge because of the low transverse velocity deficiency between pier and beam. Meanwhile, the performance of longitudinal seismic isolation with LRB is also inefficiency if the dimension of LRB is not enlarged. Consequently, it is an innovative way to make a combinative use of LRB and FVD, LRB for transverse isolation and FVD for longitudinal mitigation, to seismic isolation of multi-span continuous bridge.

In this paper, an equal section multi-span continuous bridge model based on ZhaoJiaPo bridge of Jiali highway of Guizhou province was established by use of FEM software Midas. The performance of isolation and mitigation of LRB and FVD were estimated and the influence of design parameters on the response of isolation devices was also investigated in this study. The analysis of isolated bridge model which adopt LRB and FVD at the same time indicates that the combined use of LRB and FVD is an effective way to reduce seismic response of multi-span continuous bridge and can give some advices to the design of similar bridges.

\section{Isolation principle and mechanical model of LRB and FVD}

\subsection{Isolation principle and mechanical model of LRB}

LRB consists of isolator and damper and has enough vertical stiffness to bear the dead load and live load from the superstructure. It also has an excellent horizontal flexibility that can lengthen the period of free vibration of bridge structure. Recrystallization of the lead core under earthquake motion will increase the damping of structure and dissipate energy. Many research findings revealed that LRB has an outstanding performance in energy dissipating. Fig.1 shows the experimental hysteretic curves of LRB under alternating load.

The yielded lead core under earthquake excitation decrease stiffness of structure and lengthen period of free vibration, meanwhile the plastic deformation of lead core absorb the energy of earthquake and dissipate it. Designer can adopt different design parameters such as the number and diameter of lead core to give a suitable seismic design according to different seismic intensity and diverse vibration characteristics of bridge. The basic function of bearing is to support the superstructure so there are two basic requirements of bearing under service date. One is the vertical ultimate capacity and the other one is the resistance of brake power and wind load. Both requirements can be reached by the adjustment of design parameters of bearing. Moreover, although the existence of lead core makes big initial shear stiffness of bearing, the resistance of creep load is still at a low level according to the Fig.2. All the mechanical characters described above make LRB become an excellent choice of seismic design of multi-span continuous bridge. 

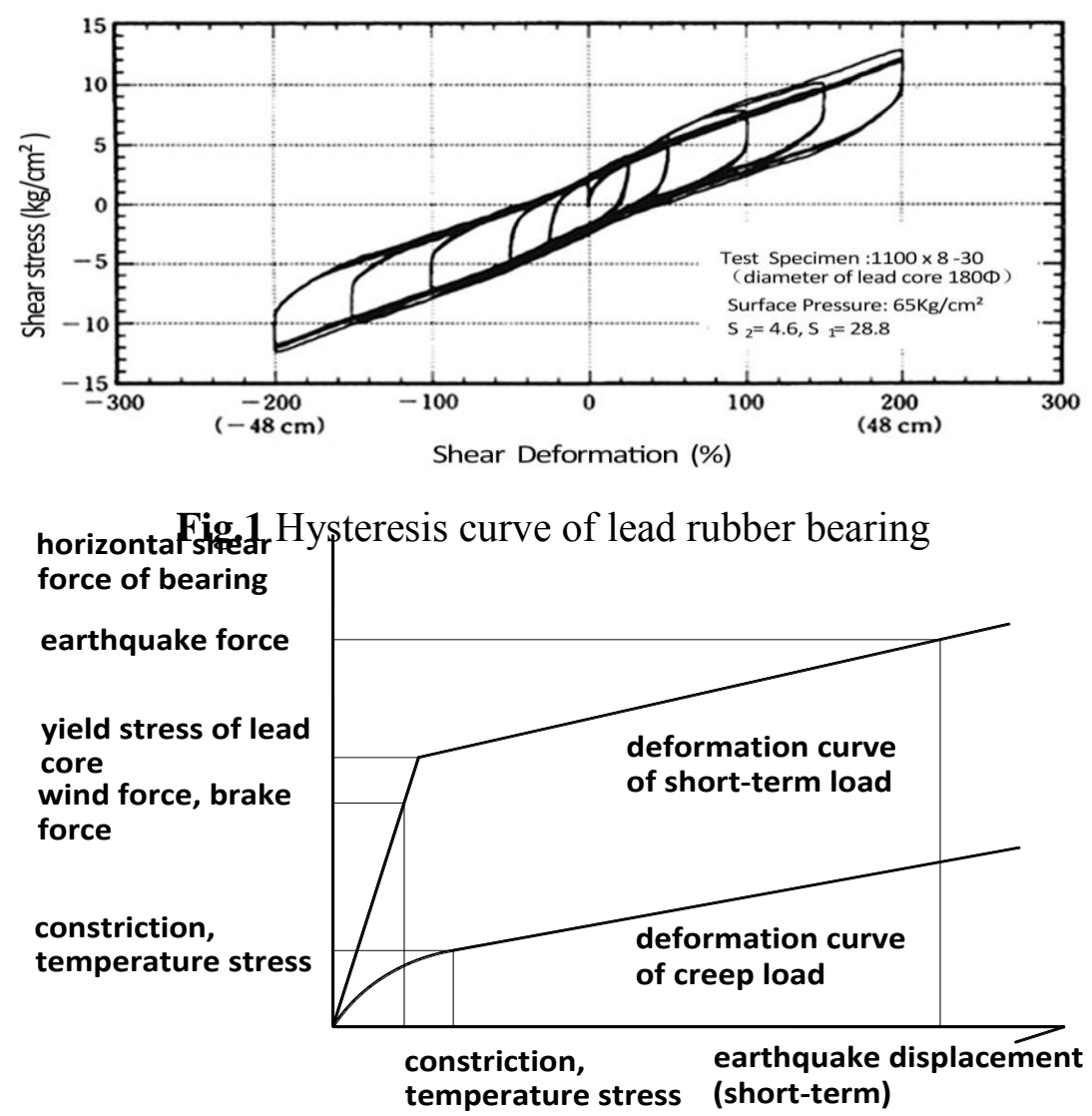

Fig.2 Resistance of lead rubber bearing under different load

FEM software MIDAS offers a kind of boundary element to simulate LRB and this kind of model adopt bidirectional restoring force theory advanced by PARK. The model of LRB used by MIDAS has a biaxial plasticity in shear elastic support of $\mathrm{X}$ axis and $\mathrm{Y}$ axis. By calculating of the modified double-linear model, the design parameters including yield strength, post yield stiffness and hardening ratio can be founded. In addition, FEM software MIDAS regards the effect of isolator as a kind of internal force and would not update the element stiffness matrix. The software calculates nonlinear characteristic indirectly by transforming the internal force to external load. The bidirectional restoring force-displacement hysteresis model shown in Fig.3 was advanced by PARK and generally recognized by the academic circles [16,17].
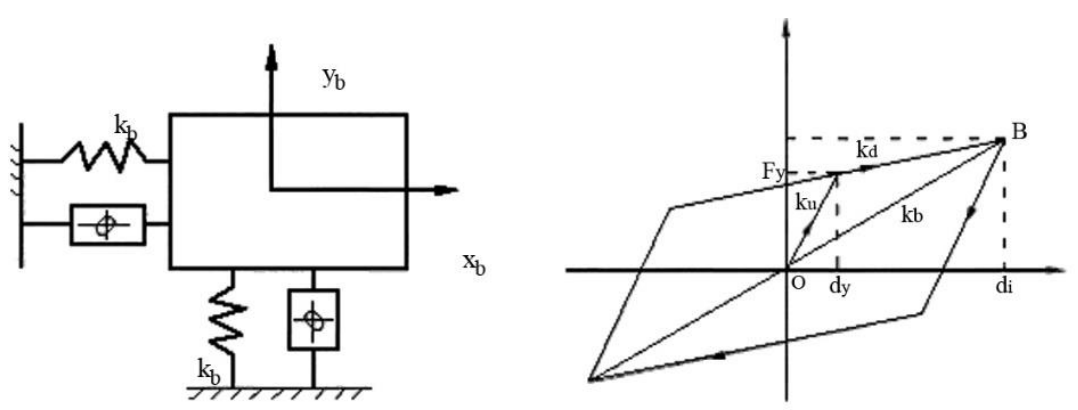

Fig.3 Bidirectional restoring force-displacement hysteresis model

The restoring force of $\mathrm{x}$ and $\mathrm{y}$ direction are represented by the following equation.

$$
\left\{\begin{array}{l}
F_{b x} \\
F_{b y}
\end{array}\right\}=r\left[\begin{array}{cc}
k_{1} & 0 \\
0 & k_{1}
\end{array}\right]\left\{\begin{array}{l}
x_{b} \\
y_{b}
\end{array}\right\}+(1-r) F_{y}\left\{\begin{array}{l}
Z_{x} \\
Z_{y}
\end{array}\right\}+\left[\begin{array}{cc}
c_{b} & 0 \\
0 & c_{b}
\end{array}\right]\left\{\begin{array}{c}
\dot{x}_{b} \\
\dot{y}_{b}
\end{array}\right\}
$$


Where $F_{b x}$ and $F_{b y}$ denote the restoring force of $x$ and y direction of lead rubber bearing; $Z_{x}$ and $Z_{y}$ stand for components of hysteretic displacement that take effect of bidirectional coupling into consideration; $c_{b}$ is the viscous damping; $k_{1}$ represents initial stiffness; $x_{b}$ and $y_{b}$ signify relative displacement of $\mathrm{x}$ and $\mathrm{y}$ direction; $r$ is hardening ratio of initial stiffness and post-yield stiffness; $F_{y}$ is the yield strength.

The bidirectional coupling and nonlinear characteristics of hysteretic displacement is shown in the following equation.

$$
\begin{aligned}
& d_{y}\left\{\begin{array}{l}
\dot{Z}_{x} \\
\dot{Z}_{y}
\end{array}\right\}=[G]\left\{\begin{array}{c}
\dot{x}_{b} \\
\dot{y}_{b}
\end{array}\right\} \\
& {[G]=\left[\begin{array}{ll}
A-\alpha \operatorname{sign}\left(\dot{x}_{b}\right)\left|Z_{x}\right| Z_{x}-\beta Z_{x}^{2} & -\alpha \operatorname{sign}\left(\dot{y}_{b}\right)\left|Z_{y}\right| Z_{x}-\beta Z_{x} Z_{y} \\
-\alpha \operatorname{sign}\left(\dot{x}_{b}\right)\left|Z_{y}\right| Z_{x}-\beta Z_{x} Z_{y} & A-\alpha \operatorname{sign}\left(\dot{y}_{b}\right)\left|Z_{y}\right| Z_{y}-\beta Z_{y}^{2}
\end{array}\right]} \\
& \operatorname{sign}(x)= \begin{cases}0 & (x=0) \\
-1 & (x<0) \\
1 & (x>0)\end{cases}
\end{aligned}
$$

Unlike unidirectional hysteretic displacement, the hysteretic displacement of two directions constituted a non-diagonal matrix $\mathrm{G}$ which embodied the coupling character of bidirectional restoring force.

\subsection{Mitigation principle and mechanical model of FVD}

The viscous damping caused by viscosity properties of medium and the effect of orifice will dissipate the vibrational energy when the convection of viscous fluid medium through the orifice occurs under the earthquake or wind excitation. That is the energy dissipation mechanism of FVD and can make a great contribution to the reduction of dynamical response of structure.

The resistance of FVD is only related to the relative velocity of piston and cylinder block once the design parameters of FVD are determined. The equation is:

$$
F=C v^{\alpha}
$$

Where $F$ denotes damping force; $C$ represents damping coefficient which related to the size of bearing; $v$ stands for relative velocity of piston and cylinder; $\alpha$ signifies damping exponent related to the viscosity of the medium and the diameter of the orifice and its values range from 0.1 to 2.0.

Five mechanical models have been developed to simulate FVD in the seismic analysis. They are: Maxwell model, Kelvin model, Wiechert model, fractional derivative model and finite element model. Maxwell model is used very often in bridge seismic isolation analysis. As shown in Fig.4, Maxwell model consists of two components which work in tandem, one is the damping characteristics and the other one is the connection stiffness. This method coincides well with the physical truth.

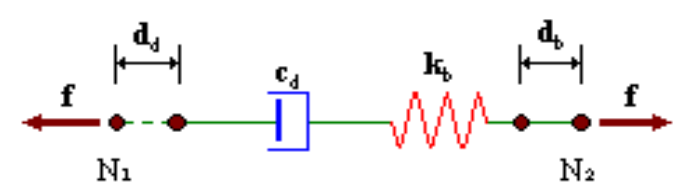

Fig.4 Maxwell model

The restoring force equation of Maxwell model is: 


$$
f=C_{d} \operatorname{sign}\left(\dot{d}_{d}\right)\left|\frac{\dot{d}}{v_{0}}\right|^{S}
$$

Where $C_{d}$ denotes damping coefficient; $v_{0}$ stands for the reference value of velocity; $S$ is the damping exponent which decide the nonlinear characteristics of damper (the direction of damping force is opposite to the direction of velocity of displacement and proportionate to the $S$ square of absolute value of velocity)

FEM software MIDAS provides an option called 'viscoelastic damper' which is a kind of boundary element to simulate FVD in seismic analysis. MIDAS also adopts Maxwell model to give an analog to mechanical characteristics of FVD and calculates nonlinear characteristics indirectly like LRB.

\section{Analysis and numerical simulation of seismic isolation system of equal section multi-span continuous beam bridge}

\subsection{Calculation model and calculation principle}

The time history dynamic analysis method was applied to obtain dynamic responses of structure in this study. For practical situation, employing distributed parameter system can reach the exact seismic response of structure but the complex of calculation is extremely tremendous. As a result, Bridge designers always simplify bridge structure to a multi degrees of freedom system in calculation and reach a reliable result.

Employing multi degrees of freedom system to calculate seismic response of structure, the displacement of nodes are divided into two categories by its location: the displacement of first node category is synchronous with ground motion such as supporting node of structure, represented by $u_{b}$; the other node category is not effected by ground motion directly and its displacement is denoted by $u_{a}$. As a result, the motional equation of structure is shown in Eq. (5).

$$
\left[\begin{array}{cc}
M_{a} & M_{a b} \\
M_{a b}^{T} & M_{b}
\end{array}\right]\left\{\begin{array}{l}
\ddot{u}_{a} \\
\ddot{u}_{b}
\end{array}\right\}+\left[\begin{array}{cc}
C_{a} & C_{a b} \\
C_{a b}^{T} & C_{b}
\end{array}\right]\left\{\begin{array}{l}
\dot{u}_{a} \\
\dot{u}_{b}
\end{array}\right\}+\left[\begin{array}{cc}
K_{a} & K_{a b} \\
K_{a b}^{T} & K_{b}
\end{array}\right]\left\{\begin{array}{l}
u_{a} \\
u_{b}
\end{array}\right\}=\left\{\begin{array}{l}
R_{a}(t) \\
R_{b}(t)
\end{array}\right\}
$$

Where $R_{a}(t)$ and $R_{b}(t)$ stand for other dynamic load except earthquake. According to principle of matrix multiplication, the first line of Eq. (5) is shown in Eq. (6).

$$
\left[\begin{array}{ll}
M_{a} & M_{a b}
\end{array}\right]\left\{\begin{array}{l}
\ddot{u}_{a} \\
\ddot{u}_{b}
\end{array}\right\}+\left[\begin{array}{ll}
C_{a} & C_{a b}
\end{array}\right]\left\{\begin{array}{l}
\dot{u}_{a} \\
\dot{u}_{b}
\end{array}\right\}+\left[\begin{array}{ll}
K_{a} & K_{a b}
\end{array}\right]\left\{\begin{array}{l}
u_{a} \\
u_{b}
\end{array}\right\}=R_{a}(t)
$$

For isolated bridge, absolute displacement method is generally used to obtain the motional equation of structure. Furthermore, the FEM software MIDAS adopts spring mass system to simulate bridge structure and the motional equation can be simplified into Eq. (7).

$$
M_{a} \ddot{u}_{a}+C_{a} \dot{u}_{a}+K_{a} u_{a}=R_{a}(t)-C_{a b} \dot{u}_{b}-K_{a b} u_{b}
$$

Eq. (7) can be further simplified into Eq. (8) when there is no other excitation except earthquake and ignoring the damping component.

$$
M_{a} \ddot{u}_{a}+C_{a} \dot{u}_{a}+K_{a} u_{a}=-K_{a b} u_{b}
$$


The absolute displacement of structure $u_{a}$ can be worked out by above equation. In addition, this study ignores rotational degrees of freedom of mass nodes.

This study is based on Zhaojiapo bridge of Jiali highway, a double-deck bridge has five spans and length of each span is $30 \mathrm{~m}$. Localized site effect of this bridge is the second kind according to Guidelines for Seismic Design of Highway Bridge [5] and relative height of piers is in a great value, so, this bridge is adaptive to adopt isolation technology. The superstructure of Zhaojiapo bridge is a simply-supported-continuous system with 30-meters standard T beam, this kind of beam has regular shape, well transverse distribution and convenience for simulating by grillage method. The substructure is consisted of column pier and friction pile, and both of them are comply with an assumption of elastic deformation. 6-DOF spatial beam elements are used to simulate the substructure and the effect of pile-soil-structure interaction is included using " $m$ law". Laminated bearing is used to connect pier and beam and sliding bearing for abutment and beam. Laminated bearing and sliding bearing are simulated with three-way linear spring model.

For comparison, the left deck remains original design and the right deck adopted seismic design. Horizontal and vertical stiffness of spring element are obtained through the method offered by Guidelines for Seismic Design of Highway Bridge [5]. Fig.5 shows graphically the analytical model of single deck continuous bridge. Three ground motions (1940, EI Centro Site, 270 Deg( Elcent-h)、 1940, EI Centro Site, 180 Deg( Elcent-t), 1971, San Fernando, 69 Deg( Sanfer-h) ) are adjusted to make sure the duration is 10 times larger than the period of structure and adopted as the earthquake excitation.

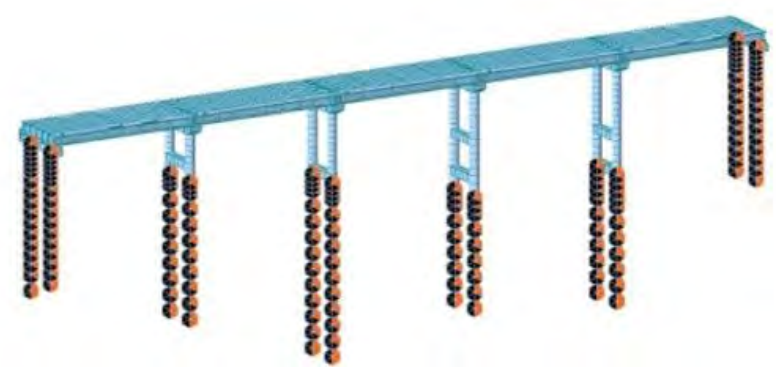

Fig.5 Calculation model of equal section multi-span continuous beam bridge (from left side to right side, the identifier of abutments and piers are $0 \# \sim 5 \#)$

\subsection{The seismic performance of lead rubber bearing}

\subsubsection{Transverse seismic performance of lead rubber bearing}

According to the linear time history analysis of left deck bridge without seismic isolation design, the most unfavorable loading condition occurs on the number 4 pier which the bending moment is $5024 \mathrm{kN} \cdot \mathrm{m}$ and axial force is $6443.8 \mathrm{kN}$ under the transverse earthquake excitation. The ultimate bearing capacity of bending moment of number 4 pier is only $4555.9 \mathrm{kN} \cdot \mathrm{m}$ and the value of axial force is $5833.8 \mathrm{kN}$ according to the computational method offered by code for design of highway reinforced concrete and prestressed concrete bridges and culverts [18]. So, the result indicates that left deck bridge will becoming failure under earthquake load and it is necessary to redesign it with seismic technology. The seismic isolation design of right deck bridge replaces all laminated bearing to lead rubber bearing and design parameters of lead rubber bearing are shown in Table 1 (the investigation of effect of design parameters of LRB will present in another paper). Typical bridge transverse response time curves before and after isolation under EIcent-h wave are shown in Fig.6. Use damping-isolation ratio to represent the contribution of lead rubber bearing to the reduction of seismic response of structure and the results are shown in Table 2. 
Table 1 Design parameters of lead rubber bearing

\begin{tabular}{cccccccc}
\hline $\begin{array}{c}\text { Type } \\
\text { of } \\
\text { bearing }\end{array}$ & $\begin{array}{c}\text { Diameter of } \\
\text { bearing(mm) }\end{array}$ & $\begin{array}{c}\text { Numbers } \\
\text { of lead } \\
\text { core }\end{array}$ & $\begin{array}{c}\text { Diameter } \\
\text { of lead } \\
\text { core }(\mathrm{mm})\end{array}$ & $\begin{array}{c}\text { Yield } \\
\text { strength } \\
(\mathrm{kN})\end{array}$ & $\begin{array}{c}\text { Post-yield } \\
\text { stiffness } \\
\mathrm{K}_{2}(\mathrm{kN} / \mathrm{m})\end{array}$ & $\begin{array}{c}\text { Equivalent } \\
\text { stiffness } \\
(\mathrm{kN} / \mathrm{m})\end{array}$ & $\begin{array}{c}\text { Equivalent } \\
\text { damping } \\
\text { ratio }\end{array}$ \\
\hline $\begin{array}{c}\text { LRB } \\
(48)\end{array}$ & 575 & 4 & 48 & 61.525 & 2689.5 & 3296.9 & 0.1 \\
\hline \multicolumn{7}{c}{ Table 2 Damping-isolation ratio of bridge structure } \\
\hline Pier & Displacement of & Displacemen & Shear force of & Bending moment of \\
number & top of pier & t of beam & bottom of pier & bottom of pier \\
\hline 1\# & 53.0 & 54.5 & 55.8 & 56.5 \\
$2 \#$ & 39.6 & 38.5 & 30.1 & 36.3 \\
$3 \#$ & 37.4 & 32.1 & 39.2 & 38.5 \\
$4 \#$ & 37.4 & 34.0 & 34.4 & 34.0 \\
\hline
\end{tabular}

(damping-isolation ratio $=($ response of left deck bridge-response of right deck bridge)/ response of left deck bridge $\times 100 \%$ )

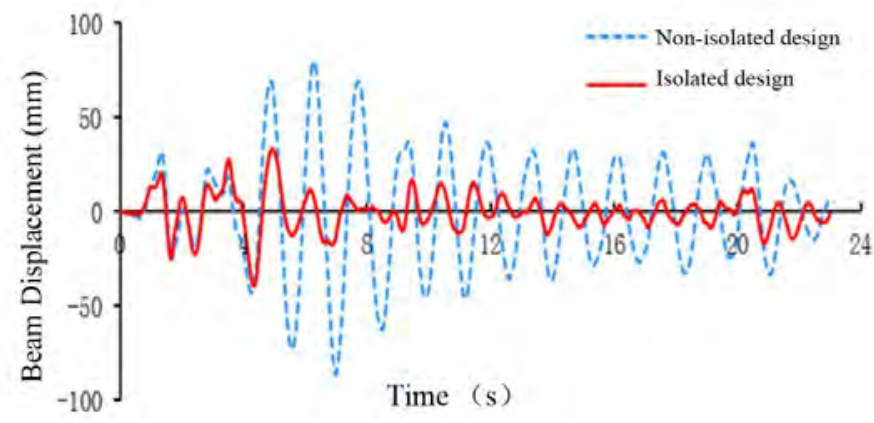

Fig.6 Time-history curves of transverse beam displacement

The results shown in Fig. 6 and Table 2 reveal that the dynamical response of bridge is reduced to a great extent when equipped with lead rubber bearing, the displacement of pier top is reduced by $53 \%$ maximally; the largest decrease of displacement of beam is $54.5 \%$; shearing force of the pier bottom is reduced by $55.8 \%$ maximally; bending moment of the pier bottom is reduced by $56.5 \%$ maximally. The above data give reliable evidence that lead rubber bearing can restrain the adverse affects of earthquake and dissipate seismic energy greatly compared to the laminated bearing. The pier ultimate bearing capacity of bending moment and axial force of right deck bridge equipped with lead rubber bearing is $6206.5 \mathrm{kN} \cdot \mathrm{m}$ and $12378.7 \mathrm{kN}$ which are far overweigh the most unfavorable load values of $2736.7 \mathrm{kN} \cdot \mathrm{m}$ and $5462.6 \mathrm{kN}$ and the deformation of structure is still in the elastic region under the load is acting. In addition, the biggest value of displacement of beam is $59 \mathrm{~mm}$, less than the distance $(85 \mathrm{~mm})$ between the beam and transverse shear key.

\subsubsection{Longitudinal seismic performance of lead rubber bearing}

Turn the transverse ground motion to longitudinal ground motion and keep the same ground motion parameters with the former study. The longitudinal seismic performance of lead rubber bearing is obtained by linear time history analysis of left deck and right deck bridge through FEM software MIDAS. Fig. 7 shows longitudinal displacement of the pier top and longitudinal bending moment on the pier bottom of left and right deck bridge under the earthquake load. 


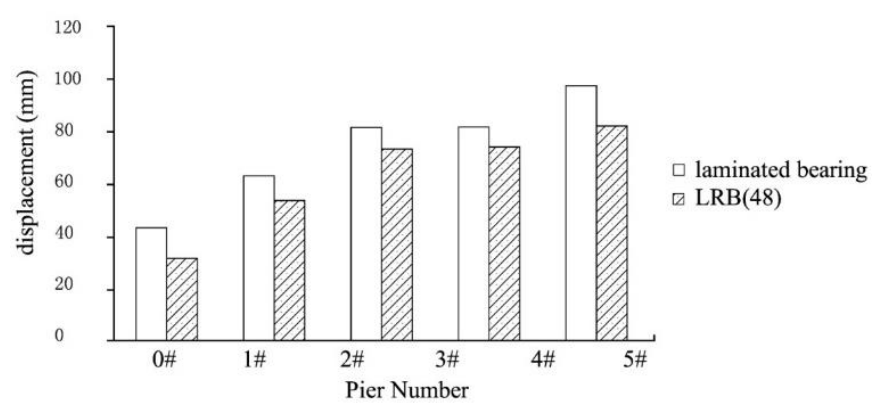

(a)

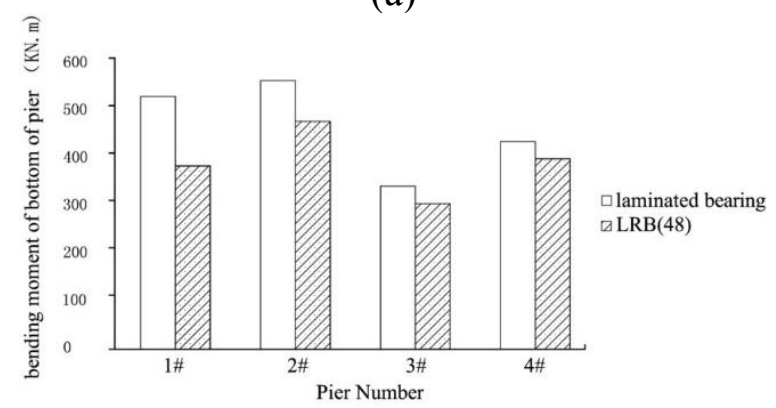

(b)

Fig.7 Longitudinal seismic response of bridge under Sanfer-h seismic wave: (a) Longitudinal displacement of beam and pier top; (b) Longitudinal bending moment of bottom of pier

The results shown in Fig.7 indicate that the longitudinal seismic response far overweigh the transverse response whether the bridge is seismic isolated. This is because the shape of bridge structure is narrow and the transverse flexibility is less than longitudinal flexibility. The first vibration mode of bridge is longitudinal translation of beam also give an evidence of the longitudinal dynamical response is dominant. It is also revealed in the Fig. 7 that the isolated bridge equipped with lead rubber bearing performs better than left deck un-isolated bridge to some extent under E2 earthquake. But, under Sanfer-h seismic wave, the longitudinal displacement of beam $(90 \mathrm{~mm})$ is still bigger than the width of expansion joints $(80 \mathrm{~mm})$ and it might lead to the collision of beam and abutment. Furthermore, the internal force of the pier bottom of isolated bridge is at a high level yet and might result in plastic failure or even brittle failure when the pier concrete is less of reinforcing bar.

In conclusion, the seismic isolation system only use lead rubber bearing (48) could not ensure the safety of bridge in longitudinal and transverse dynamical responses simultaneously. If designer want to reduce seismic response through adopting lager bearings, it is also hard to meet the structural requirements of cushion stone and space under the beam. It is a convenient way to add another seismic isolation device to ensure the safety of structure. The fluid viscous damper has powerful capacity of limiting displacement and energy dissipating and it also easy to install, so, it is widely used in bridge seismic isolation.

\subsection{The Seismic mitigation performance of fluid viscous damper}

Add two fluid viscous dampers on the abutments both sides symmetrically of right deck bridge and all bearings are remain original design. The damping coefficient $C$ values 1000 and the damping exponent $\alpha$ values 0.3 . With linear elastic assumption, the dynamical response of right deck isolated bridge and left deck bridge, under selected seismic waves, ware investigated and the results are shown in Table 3 and Table 4. 
Table 3 Seismic response of bridge structure equipped with FVD

\begin{tabular}{|c|c|c|c|c|c|c|c|}
\hline $\begin{array}{c}\text { Seismic } \\
\text { wave }\end{array}$ & $\begin{array}{l}\text { Displac- } \\
\text { ement of } \\
\text { beam }(\mathrm{mm})\end{array}$ & $\begin{array}{c}0 \# \\
\text { bending } \\
\text { moment } \\
(\mathrm{kN} \cdot \mathrm{m})\end{array}$ & $\begin{array}{c}1 \# \\
\text { bending } \\
\text { moment } \\
(\mathrm{kN} \cdot \mathrm{m})\end{array}$ & $\begin{array}{c}2 \# \\
\text { bending } \\
\text { moment } \\
(\mathrm{kN} \cdot \mathrm{m})\end{array}$ & $\begin{array}{c}3 \# \\
\text { bending } \\
\text { moment } \\
(\mathrm{kN} \cdot \mathrm{m})\end{array}$ & $\begin{array}{c}4 \# \\
\text { bending } \\
\text { moment } \\
(\mathrm{kN} \cdot \mathrm{m})\end{array}$ & $\begin{array}{c}5 \# \\
\text { bending } \\
\text { moment } \\
(\mathrm{kN} \cdot \mathrm{m})\end{array}$ \\
\hline Elcent- $t$ & 28.3 & 383.2 & 2379.2 & 2125.6 & 1536.3 & 1986.6 & 382.7 \\
\hline Sanfer-h & 33.0 & 414.7 & 1565.7 & 2290.6 & 1409.2 & 1654.3 & 414.3 \\
\hline Elcent-h & 22.2 & 413.8 & 1857.2 & 1954.6 & 1461.4 & 1755.8 & 413.3 \\
\hline
\end{tabular}

Table 4 Damping-isolation ratio of seismic response of bridge structure equipped with FVD (\%)

\begin{tabular}{cccccrrc}
\hline $\begin{array}{c}\text { Seismic } \\
\text { wave }\end{array}$ & $\begin{array}{c}\text { Displac- } \\
\text { ement of } \\
\text { beam }\end{array}$ & $\begin{array}{c}\text { 0\# } \\
\text { bending } \\
\text { moment }\end{array}$ & $\begin{array}{c}1 \# \\
\text { bending } \\
\text { moment }\end{array}$ & $\begin{array}{c}2 \# \\
\text { bending } \\
\text { moment }\end{array}$ & $\begin{array}{c}3 \# \\
\text { bending } \\
\text { moment }\end{array}$ & $\begin{array}{c}4 \# \\
\text { bending } \\
\text { moment }\end{array}$ & $\begin{array}{c}\text { bending } \\
\text { moment }\end{array}$ \\
\hline Elcent-t & 74.3 & - & 61.8 & 68.0 & 63.5 & 65.4 & - \\
Sanfer-h & 65.9 & - & 69.8 & 58.5 & 57.8 & 61.1 & - \\
Elcent-h & 82.9 & - & 72.8 & 74.3 & 67.8 & 71.2 & - \\
\hline
\end{tabular}

(damping-isolation ratio $=($ response of left deck bridge-response of right deck bridge)/ response of left deck bridge $\times 100 \%$ )

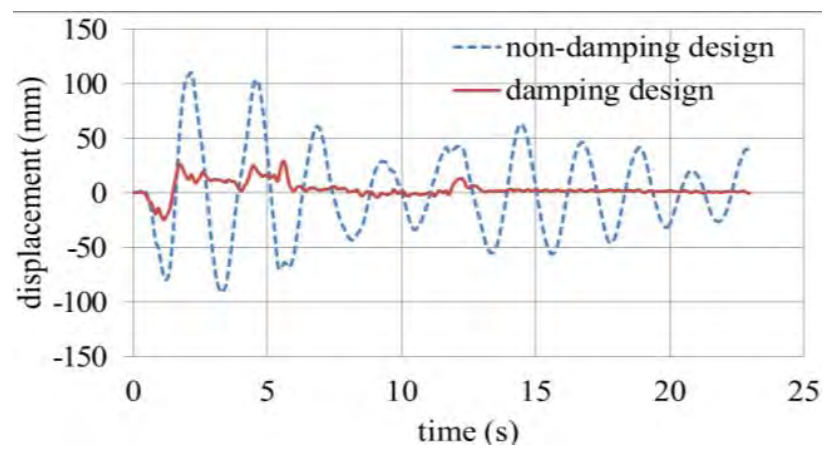

Fig.8 Time-history curves of longitudinal beam displacement

As shown in Fig.8, Table 3 and Table 4, the longitudinal displacement of isolated bridge beam equipped with fluid viscous dampers is limited under $40 \mathrm{~mm}$ and this value reduced by $82.9 \%$ maximally compared to the left deck bridge. The most unfavorable load of pier of bending moment and axial force is $1986.6 \mathrm{kN} \cdot \mathrm{m}$ and $5771.9 \mathrm{kN}$ and that is far less than the value of ultimate bearing capacity of $6426.4 \mathrm{kN} \cdot \mathrm{m}$ and $15951.6 \mathrm{kN}$. Furthermore, the value of the most unfavorable load of abutment is also far blow to its ultimate bearing capacity which $779 \mathrm{kN} \cdot \mathrm{m}$ to $4463.9 \mathrm{kN} \cdot \mathrm{m}$ and $1054 \mathrm{kN}$ to $6045.6 \mathrm{kN}$. All data above tell that the fluid viscous damper can reduce seismic response of bridge structure under earthquake to a great extent and it also protect bridge from collision of beam and abutment and drop of beam under strong ground motion.

\subsection{The combined use of lead rubber bearing and fluid viscous damper}

The analysis of using lead rubber bearing and fluid viscous damper to seismic isolation of multi-span continuous bridge respectively indicate that using one kind of seismic isolation device only could not resist the influence of earthquake. Lead rubber bearing performs well in transverse seismic isolation but its contribution to longitudinal seismic isolation is not enough. Fluid viscous damper do well in reducing longitudinal seismic response but it is not suitable adopted in transverse mitigating because of the low transverse relative speed of pier and beam. The true seismic wave is complicated and stochastic that a seismic isolation system must provide omnibearing protection. An innovative seismic isolation system consists of lead rubber bearing and fluid viscous damper is estimated in this study. 
Three analysis models are established, the first one is left deck bridge model without any seismic isolation; the second one adopt fluid viscous damper and the last one use LRB and FVD both. The layout of isolator is shown in Fig.9. Use MIDAS to obtain their dynamical response under the selected seismic waves and compare the results to each other.

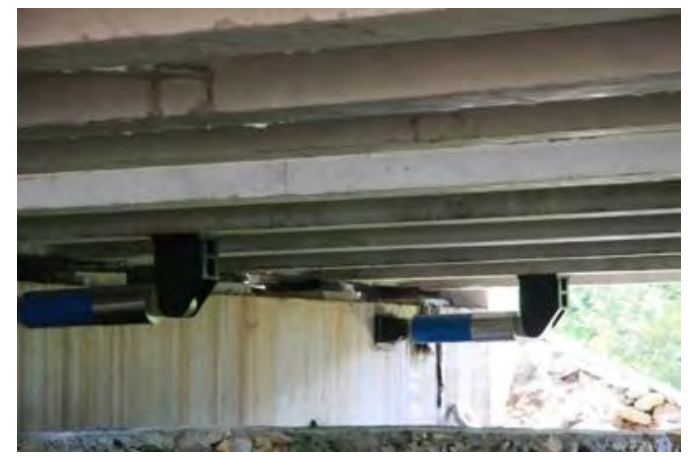

(a)

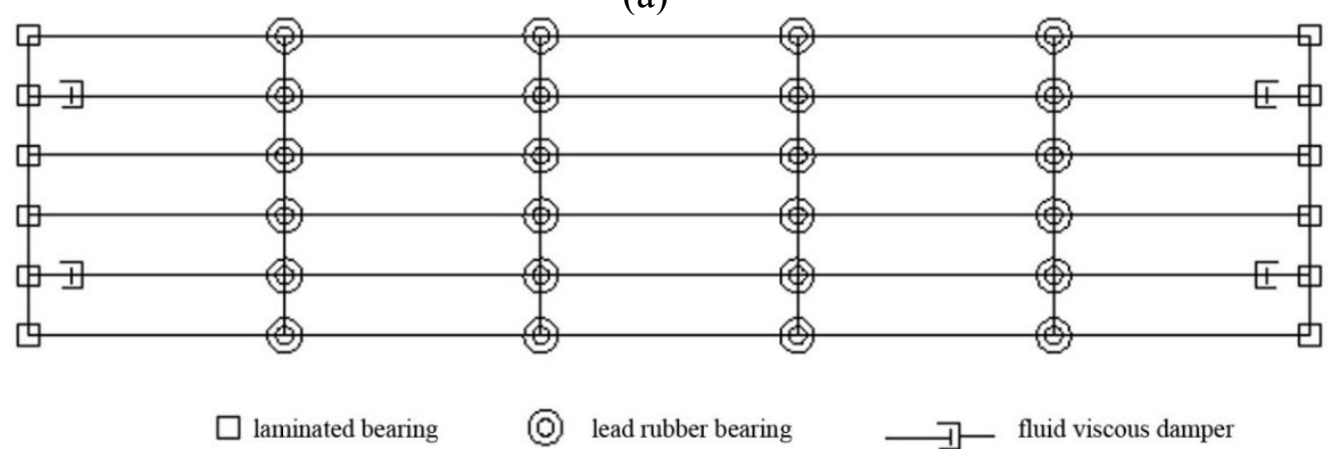

(b)

Fig.9 The layout of lead rubber bearing and fluid viscous damper: (a) Location of fluid viscous

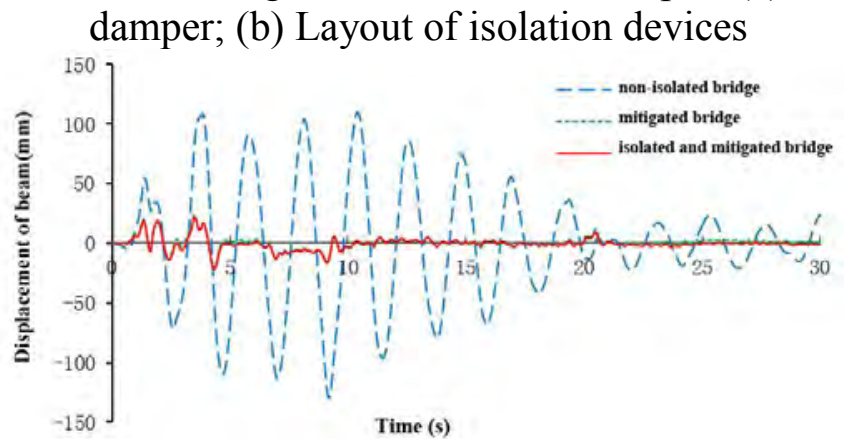

(a)

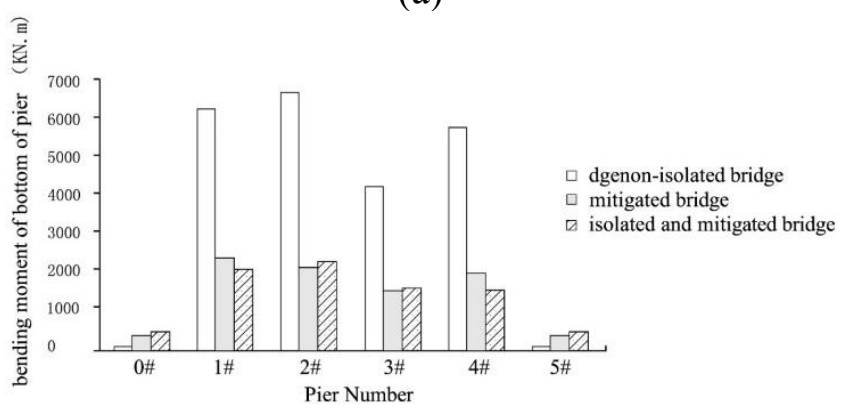

(b)

Fig.10 The longitudinal seismic response of bridge structure under EIcent-h seismic wave: (a) Longitudinal displacement of beam; (b) Longitudinal bending moment of pier bottom under Elcent- $t$ seismic wave

Both of mitigation model and isolation-mitigation model can reduce the longitudinal seismic response to a great extent and results of two models are roughly the same. It reveals that the function 
of fluid viscous damper is dominant in longitudinal energy dissipating and the function of lead rubber bearing is minor. This is because the displacement of beam is decreased a lot by fluid viscous damper and the shearing deformation of bearing is also reduced. The capacity of energy dissipating of lead rubber bearing is related to shearing deformation of lead core and it is limited by the fluid viscous damper.

\section{Experiment about combined use of LRB and FVD}

\subsection{The experimental principle and method}

The left deck of Zhaojiapo-highway bridge is equipped with LRB and FVD to defend attack of earthquake, its right deck only use the normal laminated bearing. The brake force of truck was applied to simulate the effect of earthquake and the time-dependant curves of displacement and acceleration ware investigated and recorded. The calculation result of dynamic response of structure can be verified via comparing to the experimental result and the performance of combined use of LRB and FVD can be estimated.

A dynamic data collection and analysis device MGCplus which was produced by Germany company HBM was applied in this experiment and the assorted acceleration and displacement sensors ware also used. The analysis software catman ${ }^{\circledR}$ offered a reliable method to arrange experimental statistics.

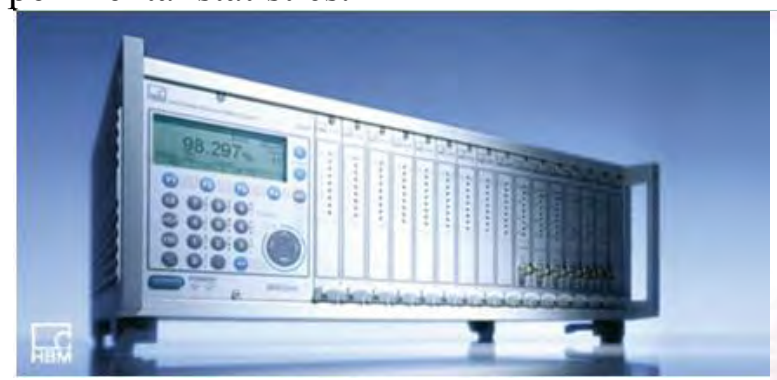

(a)

Fig.11 The instrument of brake experiment: MGCplus; (b) $t_{149}$

FEM software MIDAS was applied to get excitation source of this experiment was a $60-\mathrm{tc}_{200}$ two operating modes, operating mode 1 was und under velocity of $60 \mathrm{~km}$ per hour.

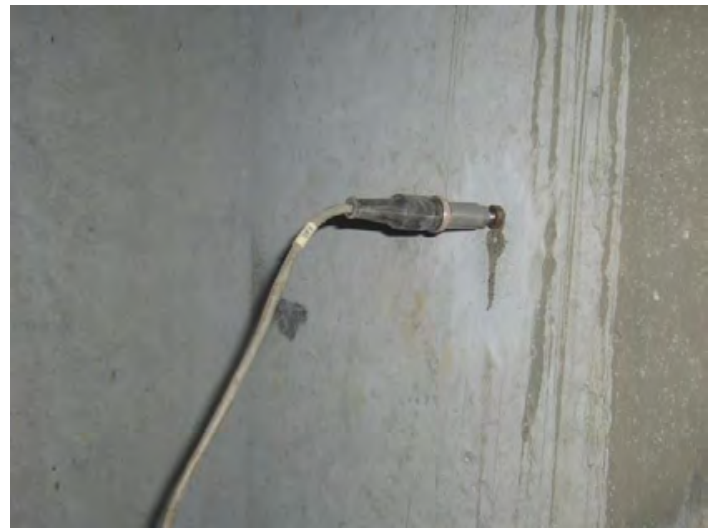

(a)
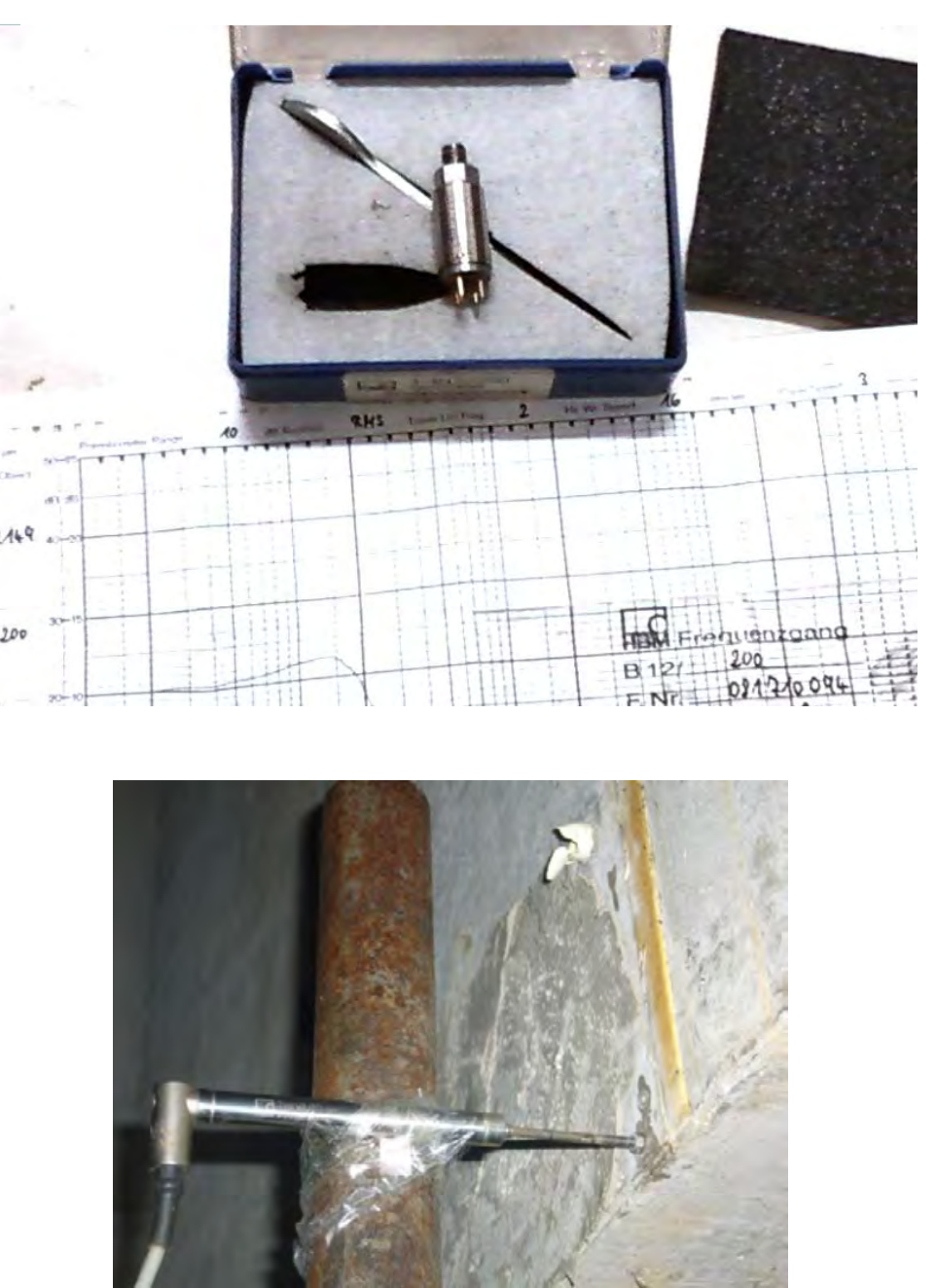

(b)

Fig.12 The installation of sensor (a) Acceleration sensor; (b) Displacement sensor

\subsection{The experimental result}

The dynamic response of bridge under brake force of truck load in operating mode 1 and mode 2 was shown in Table.5 and Table.6. The theoretical results reveal that dynamic response (displacement of beam) of bridge which equipped LRB and FVD reduced a lot comparing to the result of non-isolated 
bridge. The experimental result verified this situation and the maximum value of displacement of beam even lower than theoretical result. The experimental results was correspond to theoretical result and this consistency offer a strong evidence of considerable damping effect of combined use of LRB and FVD.

Table 5 The comparison of theoretical result and experimental result in operating mode 1

\begin{tabular}{|c|c|c|c|c|}
\hline & $\begin{array}{l}\text { Theoretical } \\
\text { result of } \\
\text { non-isolated } \\
\text { bridge }\end{array}$ & $\begin{array}{l}\text { Theoretical } \\
\text { result of } \\
\text { mitigated and } \\
\text { isolated bridge }\end{array}$ & $\begin{array}{c}\text { First time } \\
\text { experimental } \\
\text { result of mode } 1 \\
\text { under } 40 \mathrm{~km} / \mathrm{h}\end{array}$ & $\begin{array}{l}\text { second time } \\
\text { experimental } \\
\text { result of mode } 1 \\
\text { under } 40 \mathrm{~km} / \mathrm{h}\end{array}$ \\
\hline $\begin{array}{l}\text { Maximum } \\
\text { value of } \\
\text { displacement of } \\
\text { beam }(\mathrm{mm})\end{array}$ & 13.380 & 0.391 & 0.360 & 0.266 \\
\hline $\begin{array}{c}\text { Minimum } \\
\text { value of } \\
\text { displacement of } \\
\text { beam }(\mathrm{mm})\end{array}$ & -8.866 & 0.002 & -0.101 & -0.101 \\
\hline \multicolumn{5}{|c|}{ Table 6 The comparison of theoretical result and experimental result in operating mode 2} \\
\hline & $\begin{array}{c}\text { Theoretical } \\
\text { result of } \\
\text { non-isolated bridge }\end{array}$ & $\begin{array}{l}\text { Theoretical } \\
\text { result of } \\
\text { mitigated and } \\
\text { isolated bridge }\end{array}$ & $\begin{array}{c}\text { First time } \\
\text { experimental result } \\
\text { of mode } 1 \text { under } \\
60 \mathrm{~km} / \mathrm{h}\end{array}$ & $\begin{array}{c}\text { second time } \\
\text { experimental result } \\
\text { of mode } 1 \text { under } \\
60 \mathrm{~km} / \mathrm{h}\end{array}$ \\
\hline $\begin{array}{l}\quad \text { Maximum } \\
\text { value of } \\
\text { displacement of } \\
\text { beam (mm) }\end{array}$ & 14.610 & 0.549 & 0.341 & 0.411 \\
\hline \begin{tabular}{l}
\multicolumn{1}{c}{ Minimum } \\
value of \\
displacement of \\
beam $(\mathrm{mm})$
\end{tabular} & -4.389 & 0.002 & -0.069 & -0.103 \\
\hline
\end{tabular}

\section{Conclusions}

This study was based on Zhaojiapo bridge of Jiali highway of Guizhou province, several analytical models with different seismic isolation design were established through finite element method. Nonlinear dynamic time history method was used to estimate the combined use of lead rubber bearing and fluid viscous damper. According to the results of time history dynamic analysis, the following conclusions are obtained:

1) Compared with laminated bearing, lead rubber bearing can reduce transverse seismic response of bridge and dissipate earthquake energy effectively.

2) Longitudinal seismic responses overweigh transverse seismic responses apparently. The use of lead rubber bearing could ensure the safety of multi-span continuous bridge both in transverse and longitudinal direction under the E2 earthquake.

3) Fluid viscous damper make major contribution to longitudinal seismic isolation in the system and ensure the internal force and deformation at a reasonable level. The effect of lead rubber bearing in longitudinal direction is limited by fluid viscous damper.

4) Although the lead rubber bearing contributes little in longitudinal seismic isolation, it will not prevent the work of fluid viscous damper. The combined use of lead rubber bearing and fluid viscous damper can adapt complexity and randomness of earthquake well.

5). The experimental results were correspond to theoretical result and this consistency offered a strong evidence of considerable damping effect of combine use of LRB and FVD. 


\section{References}

[1] Fan Lichu, Wang Zhiqiang. The implementation of seismic isolation technology in china $[\mathrm{J}]$. JOURNAL OF VIBRATION ENGINEERING,1999,12( 2) : $173 \sim 181$.

[2] 道路橋示方書·同解說[M].V 耐震設計編,日本道路協會, 平成 8 年 12 月(1996)

[3] Eurocode 8 Sturcture In Seismic Region - Design, Part2, Bridges, Draft,1993

[4] Guide Specifications for Seismic Isolation Design, America Association of State Highway and Transportation Officials, Washington D.C.,CA.,1991

[5] JTG/T B02-01-2008, Guidelines for Seismic Design of Highway Bridge[S].Beijing: China Communications Press, 2008

[6] M.C. Constantinou Allaoua Kartoum.Analysis of compression of hollow circular elastomeric bearings[J].Engineering Structures. Volume 14,Issue 2,1992,Pages 103-111

[7] James M. Kelly, Ian D. Aiken. Experimental studies of the seismic response of structures incorporating base-isolation systems[J].Nuclear Engineering and Design Volume 127, Issue 3, 2 June 1991, Pages 329-338

[8] A. Mori A.J. Carr, N. Cooke, P.J. Moss. Compression Behaviour of Bridge Bearings used for Seismic Isolation[J]. Engineering Structures.Volume 18, Issue 5, May 1996, Pages 351-362

[9] J.S. Hwang K.C. Chang, M.H. Tsai. Composite damping ratio of seismically isolated regular bridges[J]. Engineering Structures.Volume 19, Issue 1, January 1997, Pages 55-62

[10] Fan Lichu, Wang Zhiqiang. Seismic Isolation Design of Bridge [M]. Beijing: China Communications Press, 2001

[11] R.I. Skinner, W.H. Robinson, G.H.McVerry.Seismic isolation in New Zealand[J]. Nuclear Engineering and Design. Volume 127, Issue 3, 2 June 1991, Pages 281-289

[12] Chen Yongqi, Du Yixin. Latest Development on Implementation of Fluid Viscous Damper in Structure Engineering [J]. Earthquake Resistant Engineering and Retrofitting,2006,28 (3): $65 \sim 72$

[13] Ye Aijun, Guan Zhongguo. Seismic Design of Bridge [M]. BeiJing: China Communications Press, 2002

[14] Jin Jianmin, Zhou Fulin, Tan Pin. Study on Pre-Yield Shear Stiffness of Differential Restoring Force Model for Lead Rubber Bearing [J]. ENGINEERING MECHANICS,2010,27 (10): 7〜 13

[15] Zhong Tieyi, Yang Fengli,Xia He. Design method of isolated bridge with lead rubber bearing based on energy method [J].China Railway Science,2009,30 (2): 43 48.

[16] Wen Y K. Method for random vibration of hysteretic system[J]. Journal of the Engineering Mechanics Division,ASCE,1976,102(2):249 263.

[17] Park Y J, Wen Y K and AngA H - S. Random Vibration of Hysteretic Systems Underbi-Directional Ground Motions[J]. Earthquake Engineering and Structural Dynamics, 1986,14(4):543 557.

[18] JTG D62-2004, Code for Design of Highway Reinforced Concrete and Prestressed Concrete Bridges and Culverts[S]. Beijing: China Communications Press, 2004 